\section{The Application of RUSA Standards to the Virtual Reference Interview}

Howard R. Schwartz

Howard Schwartz is Adjunct Assistant Professor, Baruch College, The City University of New York.

Correspondence concerning this column should be addressed to Barry Trott, RUSQ Editor, 7770 Croaker Rd., Williamsburg, VA, 23188; e-mail:btrott@wrl.org.

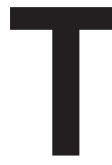

he proliferation of online databases used to search for articles in scholarly journals and magazines began shortly after Internet use became common in the late 1990s. Although there was a shift to digital resources, reference librarians still could use the same approach, asking similar questions during a reference interview, for queries involving online databases as they had during a print source search. In both cases, the patron engages the librarian in person at the reference desk. Further technological advances have created opportunities in reference service broadly defined as "virtual reference." Here, the patron only engages the librarian via e-mail or in a virtual chat over the Internet. These virtual reference encounters lack traditional visual and nonverbal cues. Thus, a new set of standards needs to be created for the reference interview in addition to defining a different form of library-patron interaction. ${ }^{1}$

\section{THE VIRTUAL REFERENCE INTERVIEW}

The original Reference and User Services Association (RUSA) guidelines for an effective reference interview had no need to include cues for the virtual environment. Now, however, a reference interview tailored to the virtual reference mode of communication is necessary as the world of reference increasingly moves beyond the traditional reference desk. Digital reference services should provide opportunities for an effective reference interview so that users can convey necessary information to librarians who would then assist the patron. ${ }^{2}$

The RUSA guidelines for implementing and maintaining virtual reference services define virtual reference as services initiated electronically, where patrons employ computers or other internet technology to communicate with reference staff without being physically present. Chat, e-mail, videoconferencing, voice over IP, cobrowsing, and instant messaging are examples of the communication channels used in virtual reference. ${ }^{3}$ This paper will focus on the interview process associated with both e-mail and chat reference, the most common methods for providing virtual reference services.

The reference interview is at the heart of the reference transaction and is crucial to the success of the process. ${ }^{4}$ Virtual reference requires that the library staff use many of the same communication and interpersonal skills that are also employed during a regular face-to-face reference transaction. For example, in the library, a well-trained librarian will sometimes initiate communication if a hesitant user appears to need assistance. This prompting can also occur in the virtual 
reference environment when a chat patron seems to pause or not respond for a period of time.

Stephanie Willen Brown defines the reference interview as the interpersonal communication that occurs between a reference librarian and a library user to determine the person's specific information needs. ${ }^{5}$ These interpersonal communication skills are perhaps even more important in virtual reference. Without the visual cues of a face-to-face interview, there is an increased need to be able to communicate clearly and effectively with patrons during a chat or e-mail encounter. These needs may turn out to be different than the initial reference question. It is more of an art than a science, an ever changing practice that requires responsiveness to context rather than to the application of a predetermined set of skills. ${ }^{6}$

Attention should be given to ensuring that a proper reference interview is provided to the patron once a library has decided upon the format that virtual reference should take. While elements of approachability, interest, listening, inquiring, searching, and follow-up are the same in both the faceto-face interview and the virtual, and principles of each apply to both formats, additional standards should be incorporated into the virtual reference interview.

\section{E-MAIL AND CHAT VIRTUAL REFERENCE}

It is important for the reader to have a clear understanding of how e-mail and chat reference function and to define both terms. E-mail is an asynchronous form of virtual reference, as the librarian and user will not interact with each other at the same time. This is also known as "non-real time reference," or delayed interaction between the library professional and the user. ${ }^{7}$

Chat reference or instant messaging, on the other hand, is synchronous, providing the librarian and patron with a real-time computer conferencing system that allows two or more persons to chat online at the same time. A chat session is initiated by typing a message in a designated window, or "chat-room," generated by the instant messaging software. The message is almost instantly displayed on the screen and the recipient is given a chance to respond. According to the Online Dictionary for Library and Information Science, chat reference is designed to deliver virtual reference services to remote users and those who prefer to instantaneously communicate online, rather than wait for an e-mail response or to come into the library for a traditional reference interview.

Matteson, Salamon, and Brewster conducted a systematic review of research on chat reference in order to further their understanding of chat services. Their aim was to analyze and integrate the literature on chat reference to uncover larger themes of knowledge in the field of reference work by synthesizing research conducted over a fifteen-year period. ${ }^{8}$

The authors chose articles for their study that examined some aspect of chat reference service. User surveys, interviews, and chat transcripts were the main data types that the articles employed to answer their research questions. ${ }^{9}$ The authors reviewed the effect of six RUSA behavioral standards on virtual reference user satisfaction. They also conducted an analysis of topics such as users' motivation for selecting chat reference services or library staff attitudes toward chat. Matteson, Salamon, and Brewster concluded that user satisfaction regarding chat reference service was "statistically significantly" higher when the RUSA behaviors of using the patron's name, listening carefully, searching with or for the patron, providing pointers to the user, asking if the question was completely answered, and inviting the patron to come back were applied to the chat reference interview. ${ }^{10}$

\section{THE RUSA STANDARDS APPLIED TO E-MAIL AND CHAT REFERENCE}

The Reference and User Services Association guidelines for the behavioral performance for reference providers are an established and accepted standard that can be used to evaluate a reference transaction. ${ }^{11}$ Van Duinkerken, Stephens, and MacDonald conducted an extensive study where they examined 1,435 reference transactions within the chat environment to determine whether they complied with the behavioral components within five basic components of a reference transaction. These five components are approachability, interest, listening/inquiring, searching, and follow-up. Each chat transcript was separately coded to see whether it complied with each RUSA recommended behavior. Each RUSA standard was coded as to yes or no depending on whether the chat reference transcript adhered to the elements of that particular behavior. ${ }^{12}$ For example if that transcript showed that the approachability RUSA behavioral standard of "presence" was met because the library had a link on its website that indicated hours of availability, then that chat transcript received a yes for approachability/presence.

Van Duinkerken, Stephens, and MacDonald conducted their research at the University of Texas Libraries and concluded that more than 75 percent of the chat transcripts demonstrated evidence of a behavior in compliance with RUSA standards. The authors concluded that adherence to the RUSA guidelines at the University of Texas Libraries was strong. ${ }^{13}$

The Reference and User Services Association has identified approachability as the first element necessary to ensure a successful reference interview. When a patron comes to the reference desk to speak to a librarian, he or she may be nervous and ill at ease. Perhaps this is the patron's first encounter with a reference librarian, and he or she is not sure of his or her research topic. Thus, it is important for the patron to be confident that a reference librarian is available to provide assistance. Also, he or she should feel comfortable going to that professional for help. The librarian's initial responses will set the tone for the entire communication process and influence the depth of the interaction between the librarian and the patron..$^{14}$ Stephanie Willen Brown contends that the patron must feel that he or she can ask a question in a traditional 


\section{FOR YOUR ENRICHMENT}

reference interview. It is important for the librarian to make eye contact as a sign of respect when the patron approaches, to stand up and incline her head to show willingness to answer the question. ${ }^{15}$

There is obviously no face-to-face interaction between the librarian and the patron in a virtual reference environment, so the approachability element needs to be addressed in a different manner. In the chat and e-mail environment, the approachability standard can be met by placing contact information about the library's virtual reference services in prominent locations. Placing the information both in the library and online would make the service more obvious to the patrons and more welcoming. When the user clicks on the chat or e-mail icon, he or she should be taken to a webpage where the chat or e-mail service is explained and the hours of operation are specified. ${ }^{16}$ The chat and e-mail service should also be advertised on signs in the libraries, as well as in bibliographic and student orientation classes. ${ }^{17}$ Jargon free links to all forms of reference service from the library's homepage should be provided, and the web should be used to make reference services easy and convenient to find. ${ }^{18}$ The level of virtual reference service that the library provides should be clearly defined so that staff and patrons will understand the mission of the service and feel comfortable using it. RUSA has defined "level of service" as including the types of questions the service will answer as well as the patron population the service provides. ${ }^{19}$

A number of other factors need to be included in order for the librarian to meet the RUSA guideline of approachability. The librarian must be poised and ready to answer a chat question, and the patron should not wait any longer than one minute before the chat provider accepts the question. A welcome message should be provided when the chat user enters the chat system. Also, if the chat provider is helping another patron, then he or she should take the time to acknowledge the waiting patron and perhaps answer his question first if it is just a directional or ready-reference query. ${ }^{20}$

A librarian conducting a successful reference interview must also demonstrate a high degree of interest in the reference transaction. Adherence to the interest guideline calls for librarians to demonstrate a commitment to providing effective information assistance. The librarian must maintain or establish "word contact" with the patron in a text-based virtual reference environment by sending written or prepared prompts to convey interest in the patron's question. Jessica Bell and April Levy define "word contact" as the written equivalent to initiating and maintaining eye contact, nodding, and other gestures used in communication. They view word contact as crucial to establishing the personal nexus with the user. ${ }^{21}$ Interest can also be shown when reference policies and procedures are clearly accessible on the library website. This helps the patron understand the types of questions that they can ask in a chat or e-mail setting and the types of answers that the service provides in a given time-frame. ${ }^{22}$

One of the most important components of any reference interview, whether virtual or face-to-face, is listening and inquiring. This third RUSA guideline emphasizes that the librarian must listen effectively as the patron states his or her information need. Once the patron has completed the initial reference inquiry, the librarian should identify the objectives of the research need and clarify the meanings of any unfamiliar words or terms..$^{23}$ Patrons must be given a chance to ask their question fully before the information provider responds or begins the search process. ${ }^{24}$ The librarian must be effective in identifying the patron's needs, since the reference interview is the heart of the reference transaction. Strong listening and questioning skills are necessary for a positive interaction.

Communication with the patron must be in a receptive, cordial, and encouraging manner, where written language or tone of voice appropriate to the nature of the transaction is used. Patrons should be allowed to fully state their information needs in their own words before the librarian responds. The information professional should rephrase the question posed in order to confirm an understanding of what the patron is asking for. Both open-ended and closed or clarifying questions should be used in order to refine the search query. 25 An open-ended question could ask for more additional information about a topic, while a closed-ended question may ask the patron for what type of information does he or she need? The librarian should rephrase the information need in his or her own words while avoiding any jargon to clarify what the patron needs. ${ }^{26}$

During a virtual reference interview, web forms or an online questionnaire should be used to gather as much information as possible without compromising user privacy. ${ }^{27}$ Eileen Abels recommends that upon receiving an e-mail reference question, the librarian should first send the user a summary of the information needs before attempting an answer. ${ }^{28}$

Proper searching behavior during the virtual reference interview is important to the patron's perception of success in his or her quest to obtain the needed information from the librarian. Without an effective search strategy, not only is the desired information unlikely to be found, but the patron may become discouraged as well. RUSA identifies a number of elements that the librarian needs to employ in order to make the search strategy effective. The librarian should find out what search strategies the patron has already tried and encourage him or her to contribute ideas during this part of the reference interview. A competent and complete search strategy should be developed where search terms and sources that are most relevant to answering the patron's query are selected. ${ }^{29}$ The search strategy should also be explained, and the librarian needs to work with the patron to narrow or broaden the topic when too much or too little information is provided. Librarians should also offer search tips so that when patrons have similar questions in the future, they will know how to find the answer. ${ }^{30}$ In a virtual reference interview, the librarian should use appropriate technology such as cobrowsing, scanning, faxing, or I-messaging to help guide patrons through the library's resources. ${ }^{31}$

The reference transaction does not end when the librarian leaves the patron. It is the librarian's responsibility to 
determine whether the patron is satisfied with the search results and to refer the patron to other sources. This final component of the reference interview is called "follow-up," where the librarian asks patrons if their questions have been answered and if they have further questions and encourages them to return if they have anything further to ask. Librarians should consult experts in the field where additional subject expertise is needed. In the virtual setting, the librarian should suggest to the patron that he or she can visit or call the library when appropriate. ${ }^{32}$ Follow-up should also include referring the patron to other sources or institutions when their query cannot be answered to the patron's satisfaction. ${ }^{33}$

\section{CONCLUSION}

Technological advances during the past decade have enabled librarians to offer both synchronous and nonsynchronous virtual reference service via the Internet. Such virtual reference service requires a virtual interview with the patron. Since there is no face-to-face contact in virtual reference between the reference provider and the patron, the virtual reference interview requires the development of unique standards. The Reference and User Services Association's elements of approachability, interest, searching, and follow-up still apply, but they need to be modified to take into account the fact that the patron is not physically present. Readily accessible information on how to use virtual reference services should be posted clearly on the library's webpage, word contact with the patron needs to be maintained, the search strategy should be explained, and the ability for the patron to follow up should be given. These modifications of the traditional reference interview will result in a positive experience for the patron using the virtual reference format.

\section{References}

1. Reference and User Services Association. Guidelines for Behavioral Performance and Information Service Providers, June 2004, accessed December 28, 2012, www.ala.org/rusa/resources/guide lines/guidelinesbehavioral, 1.

2. Ibid

3. Reference and User Service Association. Guidelines for Implementing and Maintaining Virtual Reference Services, June 2004, accessed December 29, 2012, www.ala.org/rusa/resources/guidelines/virt reguidelines, 1 .

4. Wyoma van Duinkerken, Karen L. MacDonald, and Jane Stephens, "The Chat Reference Interview: Seeking Evidence Based on
RUSA's Guidelines," New Library World 110, no. 3/4 (2009): 107.

5. Stephanie Willen Brown, "The Reference Interview: Theories and Practice," Library Philosohy and Practice (Feb. 2008), 3.

6. Kay Ann Cassell, Reference and Information in the 21st Century: An Introduction (New York: Neal-Schuman Publishers, 2006), 15.

7. Mohamed Taher, "The Reference Interview Through Asynchronous E-Mail and Synchronous Interactive Reference: Does It Save the Time of the Interviewee?" Internet Reference Services Quarterly 7 no. 3 (2002), 25.

8. Lindy Brewster, Miriam L. Matteson, and Jennifer Salamon, "A Systematic Review of Research on Live Chat Service," Reference and User Services Quarterly 51, no. 2 (2011), 173.

9. Ibid., 174 .

10. Ibid., 178 .

11. Van Duinkerken, MacDonald, and Stephens, "The Chat Reference Interview," 108.

12. Ibid., 111.

13. Ibid., 112.

14. Reference and User Services Association, Guidelines for Behavioral Performance and Information Service Providers, 2.

15. Brown, "The Reference Interview: Theories and Practice," 3.

16. Van Duinkerken, MacDonald, and Stephens, "The Chat Reference Interview," 112.

17. Ibid.

18. Reference and User Services Association, Guidelines for Behavioral Performance and Information Service Providers, 4.

19. Reference and User Services Association, Guidelines for Implementing and Maintaining Virtual Reference Services, 3.

20. Van Duinkerken, MacDonald, and Stephens, "The Chat Reference Interview," 112.

21. Jessica G. Bell and April P. Levy, "Making the Digital Connection More Personal," in The Virtual Reference Experience: Integrating Theory into Practice, ed. R. David Lankes et al. (New York: NealSchuman Publishers, Inc., 2004), 153.

22. Van Duinkerken, MacDonald and Stephens, "The Chat Reference Interview," 113.

23. Ibid., 114.

24. Ibid.

25. Reference and User Services Association, Guidelines for Behavioral Performance and Information Service Providers, 5.

26. Van Duinkerken, Macdonald, and Stephens, "The Chat Reference Interview," 113.

27. Reference and User Services Association, Guidelines for Implementing and Maintaining Virtual Reference Services, 5.

28. Eileen G. Abels, "The E-Mail Interview," RQ 35, no. 3 (Spring 1996): 11 .

29. Reference and User Services Association, Guidelines for Behavioral Performance and Information Service Providers, 5

30. Van Duinkerken, MacDonald, and Stephens, "The Chat Reference Interview," 115.

31. Reference and User Services Association, Guidelines for Behavioral Performance and Information Service Providers, 6-7.

32. Ibid., 7

33. Van Duinkerken, MacDonald, and Stephens, "The Chat Reference Interview," 121. 